\title{
Repellency of conspecific and heterospecific larval residues to Hippodamia convergens (Coleoptera: Coccinellidae) ovipositing on sorghum plants
}

\author{
J.P. MICHAUD and J.L. JYOTI \\ Department of Entomology, Kansas State University, Agricultural Research Center - Hays, $1232240^{\text {th }}$ Ave, Hays, KS 67601, USA; \\ e-mail:.jpmi@ksu.edu
}

\begin{abstract}
Key words. Coccinellidae, cannibalism, Hippodamia convergens, Coleomegilla maculata, deterrence, larval residues, intraguild
\end{abstract} predation, oviposition, Schizaphis graminum, Sorghum bicolor

\begin{abstract}
We examined oviposition decisions by Hippodamia convergens Guérin in semi-natural arenas in the laboratory. Gravid females were presented individually with an array of four young sorghum plants, Sorghum bicolor, bearing (1) no additional stimulus, (2) an established colony of greenbug, Schizaphis graminum Rondani, (3) residues of conspecific larvae, and (4) greenbugs plus residues of conspecific larvae. Females laid no egg masses on type 3 plants, significantly fewer than expected by chance on type 4 plants, and significantly more on type 1 plants, with type 2 plants receiving expected numbers. Females laid $50 \%$ of egg masses on elements of the arena other than the plants, especially the cage screen, suggesting that females sought to distance their eggs farther from larval residues than the spacing of plants in the arena permitted $(15 \mathrm{~cm})$. When the experiment was repeated with plants exposed to larvae of Coleomegilla maculata DeGeer, the repellency was weaker. Once again, clean plants were the most preferred and aphids did not increase the acceptability of plants with larval residues. Nevertheless, only $18 \%$ of egg masses occurred off the plants and larval residues did not reduce the acceptability of aphid-bearing plants as did conspecific larval residues. Simultaneous choice tests conducted with individual third instars of both species revealed that $C$. maculata larvae consumed H. convergens eggs as readily as conspecific eggs, but $H$. convergens larvae preferred conspecific eggs to those of $C$. maculata. We conclude that $H$. convergens oviposition decisions are shaped by the risks of both egg cannibalism and predation.
\end{abstract}

\section{INTRODUCTION}

Most aphid species typically exhibit an aggregated distribution on their host plants (Wratten, 1974; Pennachio \& Tremblay, 1986; Michaud, 1999) and this is also true for cereal aphids such as the greenbug (Kring \& Gilstrap, 1983). Similarly, adult coccinellids of most species themselves exhibit contagious distributions (Elliott \& Kieckhefer, 2000; Schellhorn \& Andow, 2005), presumably as a consequence of foraging for aphid prey that are clustered in patches. Kindlmann \& Dixon (1993) showed convincingly that there exists an optimal number of coccinellid eggs that should be laid in an aphid colony to maximize the number of surviving offspring, and argued that this number is typically much less than the number required to provide adequate control. Furthermore, the clustered egg masses of aphidophagous coccinellids are prime targets for both cannibalism and intraguild predation (Mills, 1982; Schellhorn \& Andow, 1999a; Gagne et al., 2002; Cottrell, 2005), so adult females must select oviposition sites that not only afford their offspring sufficient resources to complete development, but also minimize their exposure to predictable sources of mortality. A problem arises because the established aphid colonies that possess adequate food resources for complete larval development are themselves magnets for conspecifics that will readily cannibalize egg masses, as well as other aphid predators that may also be facultative intraguild predators. Thus, we might expect female oviposition site selection to reflect a spatial compromise between prox- imity to prey and distance from egg mortality risk factors (Doumbia et al., 1998).

The presence of conspecific larvae was shown by Hemptinne \& Dixon (1991) to inhibit oviposition by female Adalia bipunctata L. Subsequently, reports appeared on the oviposition repellency of larval residues in various aphidophagous insects, initially in green lacewings, Růžička (1994), then in coccinellids (Růžička, 1997; Yasuda et al., 2000). In similar vein, Scholz \& Poehling (2000) reported on the oviposition repellency of conspecific eggs and their chemical residues in syrphids. Frechette et al. (2004) demonstrated that the deterrency of conspecific larval residues to ovipositing A. bipunctata attenuated as females aged, and with longer periods of exposure. However, most of the studies on coccinellids employed the presentation of larval residues on an artificial substrate (paper strips or disks) and often failed to include other seemingly relevant cues such as aphid prey and host plant. Some of the most intensive studies on coccinellid oviposition responses to larval residues (Růžička, 1997, 2001, 2002, 2003) all employed ten females at a time in experimental arenas. This is a possible cause for concern because studies examining both aphid parasitoids (Michaud \& Mackauer, 1995) and coccinellid predators (Hemptinne et al., 1993) have demonstrated that oviposition behavior can be strongly influenced by contact with conspecific females. Therefore, we assessed the deterrency of both conspecific ( $H$. convergens) and heterospecific ( $C$. maculata) larval residues on coccinellid oviposition behavior using solitary $H$. convergens females 
foraging on plants in semi-natural arenas, both in the presence and absence of aphid prey.

\section{MATERIAL AND METHODS}

\section{Selection of insect species}

The convergent lady beetle, Hippodamia convergens Guérin, is widely distributed across North America (Gordon, 1985) and is a key biological control agent of cereal aphids on the Great Plains (Michels et al., 2001; Brewer \& Elliott, 2004). It has two or more generations per year, depending on the availability of suitable prey for adult reproduction through summer months (Hagen, 1962; Michaud \& Qureshi, 2005, 2006). Important prey species for $H$. convergens on the Great Plains include the greenbug, Schizaphis graminum Rondani, the Russian wheat aphid, Diuraphis noxia Mordvilko, the bird cherry-oat aphid, Rhopalosiphum padi L., and the corn leaf aphid, Rhopalosiphum maidis (Fitch). Another coccinellid species, Coleomegilla maculata Degeer, occurs sympatrically with $H$. convergens over much of the Great Plains and adults of both species can often be observed foraging together on a range of cereal crops that include corn, wheat, and sorghum.

\section{Aphids}

A colony of greenbug "biotype I" was established on sorghum, Sorghum bicolor (L.), using source material collected from sorghum fields in Hays, Kansas, in June, 2005. The colony was maintained on sorghum cultivar P 8500 , a variety susceptible to greenbug biotype I, grown in metal trays $(50 \mathrm{~cm}$ long $\times$ $30 \mathrm{~cm}$ wide $\times 10 \mathrm{~cm}$ height) filled with potting soil. Trays of plants were germinated in a greenhouse under natural light and infested at the 2-leaf stage by gently shaking greenbugs from infested plants evenly across the soil. Infested trays were held at $24 \pm 2{ }^{\circ} \mathrm{C}$ in a growth chamber with illumination provided by Phillips "cool white" fluorescent light at a photoperiod of $16 \mathrm{~L}$ : 8D.

\section{Coccinellids}

Adults of $H$. convergens and C. maculata were collected from fields of cultivated sunflower, Helianthus annuus L., in Hays, Kansas during the first week of June, 2006, by dislodging them from plants directly into Plexiglas cylinders $(5.0 \mathrm{~cm}$ diam. $\times 10$ $\mathrm{cm})$ covered with vented caps. Following transport to the laboratory, adults were separated by species and then brought together in groups of 5-8 in plastic Petri dishes $(9.5 \mathrm{~cm}$ diam. $\times$ $1.0 \mathrm{~cm}$ ). Mating pairs were then separated as they formed and isolated in smaller plastic Petri dishes $(5.5 \mathrm{~cm} . \times 1.0 \mathrm{~cm})$. After several days as pairs, males were removed and the females maintained in isolation. Insects were held in a climatecontrolled growth chamber set to a diurnal temperature cycle (day : night $=25^{\circ}: 20^{\circ} \mathrm{C}$ ) with a daylength of $16 \mathrm{~L}: 8 \mathrm{D}$.

Each pair of $H$. convergens females initially received a segment of sunflower petiole as a source of hydration and a small measure of frozen eggs of Ephestia kuehniella Zeller (ca. 10 $\mathrm{mg}$ ). The feeding cycle spanned six days, each dish receiving a small measure of pulverized bee pollen (ca. $10 \mathrm{mg}$ ) on the third day, and another measure of moth eggs on the sixth day. The insects were transferred to clean dishes on the days that pollen was provided, and sunflower petioles were replaced every third day when the insects were fed. On this feeding cycle, individual females become reproductive one by one over an extended period (Michaud \& Qureshi, 2006). The first $25 \mathrm{H}$. convergens females to become reproductive were labeled with a number on the dish, and then fed Ephestia eggs daily to sustain oviposition for production of larvae to be used in experiments. All females of C. maculata were treated in this manner. The eggs of both species, normally deposited on the sides or lid of the dish, were collected daily and held under the same environmental conditions as adults until they hatched ca. four days later. Larvae of both species were reared in Petri dishes $(5.5 \mathrm{~cm}$ diam. $\times 1.0$ $\mathrm{cm}), 5-6$ per dish, on a diet of Ephestia eggs.

Female $H$. convergens destined for use in the experiment were isolated in plexiglas cylinders $(5.0 \mathrm{~cm}$ diam. $\times 10 \mathrm{~cm} \mathrm{ht})$ with ventilated plastic caps and provided an ad libitum supply of greenbugs on excised sorghum leaves, refreshed every 24-48 h, a highly suitable diet for female reproduction that results in reliable production of egg clusters on a daily basis (Michaud \& Qureshi, 2006). These containers were more cumbersome than the Petri dishes, but necessary for containing the bulk of plant material and confining smaller aphid instars that are capable of escaping under the loose-fitting Petri dish lids. Experimental females were used in experimental trials after 4-5 days on the greenbug diet (5-6 days after onset of oviposition), the period required to attain maximum ovipositional activity (Michaud \& Qureshi, 2006).

\section{Oviposition experiments}

The experiment was designed to provide each female beetle with a simultaneous choice among four plant types. Each replicate consisted of a metal tray $(8 \times 26 \times 36 \mathrm{~cm})$ filled with potting soil and then planted with clusters of 4-5 sorghum seeds (cv. P 8500) at each of four locations equidistant from each other $(\mathrm{ca} .15 \mathrm{~cm})$. Trays were watered and held on benches in a greenhouse under natural lighting until germination, whereupon emergent seedlings were thinned to leave a single plant at each location. When plants reached the 3-leaf stage $(14-18 \mathrm{~cm}$ tall), each was randomly assigned to a treatment by inserting a small plastic stake in the soil next to it labeled "A", "B", "C" or "D" to represent the four treatments (clean plant, plant + aphids, plant + larval residues, plant + aphids + larval residues). A ventilated clear plastic cylinder $(4.5 \mathrm{~cm}$ diam. $\times 25.0 \mathrm{~cm} \mathrm{ht}$. $)$ was then placed carefully over each plant and inserted into the soil to isolate it from others in the arena. The A plant was left untreated as a blank check. Treatment B and D plants were infested with greenbugs by clipping an infested plant from the stock colony, dropping it into the cylinder, and then capping it. The tray was then watered lightly and placed in a growth chamber for $24 \mathrm{~h}$ under the aforementioned environmental conditions for greenbug rearing. After this period, the tray was removed and cylinders covering the $\mathrm{C}$ and $\mathrm{D}$ plants uncapped. Four second instar $H$. convergens larvae were then introduced to each of the $\mathrm{C}$ and $\mathrm{D}$ cylinders which were then capped to confine the larvae on the plants. The tray was again lightly watered and returned to the growth chamber overnight. The following day all cylinders were removed from the plants and fine tweezers was used to remove all larvae from plants and soil within the experimental arena. Disturbed soil was flattened evenly around the plants and a circular band of clear mylar (ca. $5 \mathrm{~cm}$ wide) was then placed on the soil surface to form a barrier surrounding all 4 plants, just inside the label stakes. Loose soil was ramped up along the entire inside edge of mylar barrier and then soaked with a stream of water from a wash bottle to cement the barrier in place and seal any gaps at the soil surface. A layer of Fluon ${ }^{\circledR}$ (Insecta-slip, Bioquip Inc., Rancho Dominguez, California) was then applied around the inner surface of the mylar using a camel hair brush. The objective of this barrier was to improve retention of the female beetle within the arena by reducing her ability to climb up the cage screen (gravid females are reluctant to fly) and ensure her thorough exploration of the plants.

Strips of adhesive sponge weatherstripping were then applied around the entire perimeter of the tray and a custom-made, wire frame screen cage $(26 \times 36 \times 12 \mathrm{~cm})$ stretched over a frame made of 12 gauge insulated wire was mounted on the tray by 
inserting the corner posts in the soil and clamping the netting to the edges of the tray with document clips. A single gravid female $H$. convergens was then introduced onto the soil in the center of the tray, equidistant from all four plants, through a zippered aperture in the screen. The zipper was closed and the cage placed in a growth chamber for a period of $24 \mathrm{~h}$ under the same environmental conditions as the aphid colony. If the female laid one or more egg clusters during this time, the replicate was terminated and the location of the egg cluster(s) and number of eggs recorded; otherwise the female was left in the arena for an additional $24 \mathrm{~h}$, whereupon the replicate was terminated whether or not the female laid an egg cluster. Each female was tested only once and 4-6 replicates were conducted daily until a total of 69 replicates were completed. The experiment was then repeated with 67 replicates using larvae of $C$. maculata to treat plants in the $\mathrm{C}$ and $\mathrm{D}$ treatments.

\section{Larval egg consumption}

Freshly laid $(<24 \mathrm{~h}$ old) egg clusters of each coccinellid species were obtained attached to Petri dishes and Petri dish lids. Care was taken to combine similar-sized clusters of each species in each replicate. Each replicate was labeled with a number on the lid and a data sheet recorded the number of eggs of each type and whether they were on the lid or the base of the Petri dish. Since these Petri dishes typically had a few residual moth eggs adhering to the inner surfaces from the maternal food supply, an additional small amount of moth eggs was added to each dish (ca. $1 \mathrm{mg}$.) to equalize any variation among replicates in this regard and to make the choice test more conservative by providing a food alternative to the coccinellid eggs. A single, third instar C. maculata larva was then introduced into each dish $(n=46)$. Dishes were then oriented on a tray so that equal numbers of replicates had $C$. maculata and $H$. convergens egg clusters in upper and lower positions, respectively, to prevent any bias due to position. The tray was placed in a growth chamber under the same environmental conditions as above for a period of $24 \mathrm{~h}$, at which time it was removed and larval consumption of eggs tallied under 10x magnification using a binocular dissecting microscope. The identical experiment was then repeated with third instar $H$. convergens larvae $(\mathrm{n}=22)$ as egg predators.

\section{Statistical analysis}

Variation in cluster size among egg clusters laid in different locations was tested by one-way ANOVA (SPSS, 1998). We reasoned that each deposition of an egg mass would reflect a discrete oviposition site selection decision by a female beetle, whereas the number of eggs in a cluster would more likely be a function of egg load and other physiological factors. Therefore, we chose to analyze the distribution of egg clusters among plant types, rather than total numbers of eggs laid. Considering only egg clusters laid on plants, a Chi-square, Goodness-of-fit test was used to determine whether egg clusters were deposited on plants of any type more or less often than expected by chance (expected number for any plant type $=$ total egg masses $\times .25$, assuming no effect of plant treatment). Significance levels for these Chi-square values were then determined by consulting a table of critical values of the Chi-square distribution with 3 d.f. (Rohlf \& Sokal, 1969). Next, a paired t-test (with Bonferroni correction for multiple comparisons) was used to compare (1) A vs B plants, i.e. whether the presence of aphids increased or decreased the acceptability of plants, (2) A vs C plants, i.e. whether the presence of larval residues increased or decreased the acceptability of plants, and (3) C vs D plants, i.e. whether the presence of larval residues increased or decreased the acceptability of plants with aphids. Numbers of eggs consumed by larvae from clusters of each type in the larval consumption assay were compared using a paired T-test (SPSS, 1998).

\section{RESULTS}

\section{Conspecific larval residues}

A total of $64 H$. convergens females laid one or more egg clusters in a trial - four females did not lay in the 48 $\mathrm{h}$ period and one died during the trial. A total of $91 \mathrm{egg}$ clusters were obtained containing a total of 1819 eggs (mean $=19.99 \pm 0.95$ eggs per cluster), $49.4 \%$ on the plants and $50.6 \%$ on other elements of the arena. Of the 64 females, 26 laid clusters off the plants, usually on the cage screen, but sometimes on the mylar, and in two cases, on the bare soil. Of the 38 females laying one or more egg clusters on plants, 11 also laid additional clusters elsewhere in the arena. There was no significant difference in egg number among clusters laid on plants with or without aphids or on various elements of the arena $(F$ $=0.44$, df $=2, P=0.64)$; insufficient clusters were laid on plants with larval residues, either with or without aphids, to include these treatments in the analysis of cluster size.

The numbers of egg masses obtained on each of the four plant types is depicted in Fig. 1. Significantly more egg clusters were laid on clean plants (treatment A) than would be expected by chance $\left(\chi^{2}=17.8, \mathrm{df}=3,0.001<\right.$ $\alpha<0.005)$, whereas egg clusters were laid on plants with aphids (treatment B) at a frequency similar to that expected by chance $\left(\chi^{2}=3.63\right.$, df $\left.=3,0.1<\alpha<0.5\right)$. In contrast, plants with only larval residues (treatment $\mathrm{C}$ ) were avoided completely $\left(\chi^{2}=11.0,0.01<\alpha<0.05\right)$, and the addition of aphids (treatment D) did little to amelio-

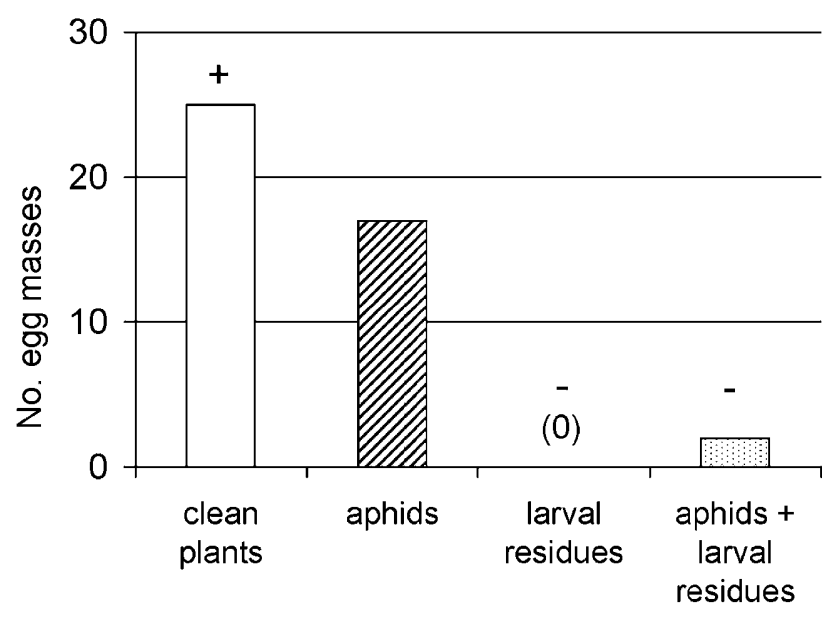

Fig. 1. Numbers of egg masses laid by 38 Hippodamia convergens females on four types of 3-leaf sorghum plants when tested individually in experimental arenas for 24-48 h. Plant treatments were: (1) no additional stimulus (clean plants), (2) a colony of Schizaphis graminum (aphids), (3) residues of conspecific larvae (larval residues), and (4) a colony of $S$. graminum and conspecific larval residues (aphids + larval residues). Plus and minus signs indicate plant types receiving significantly more or fewer egg masses, respectively, than would be expected by chance if no plant type were preferred over any other (Chisquare, Goodness-of-fit test, $P<0.05$ ). 


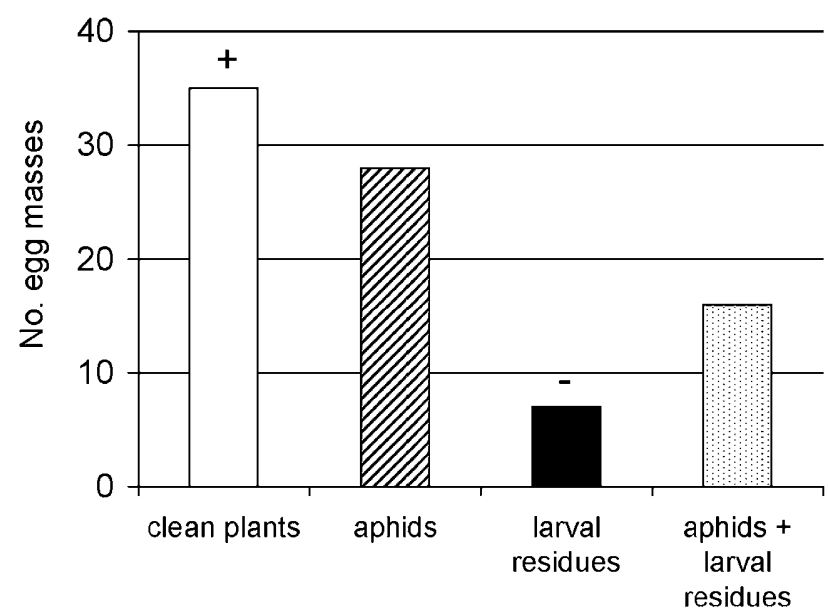

Fig. 2. Numbers of egg masses laid by 56 Hippodamia convergens females on four types of 3-leaf sorghum plants when tested individually in experimental arenas for 24-48 h. Plant treatments were: (1) no additional stimulus (clean plants), (2) a colony of Schizaphis graminum (aphids), (3) residues of Coleomegilla maculata larvae (larval residues), and (4) a colony of $S$. graminum and C. maculata larval residues (aphids + larval residues). Plus and minus signs indicate plant types receiving significantly more or fewer egg masses, respectively, than would be expected by chance if no plant type were preferred over any other (Chi-square, Goodness-of-fit test, $P<0.05$ ).

rate their deterrency $\left(\chi^{2}=7.36,0.05<\alpha<0.1\right)$. Pairwise comparisons of plant treatments revealed that larval residues significantly reduced the acceptability of plants with aphids $(T=4.91, \mathrm{df}=37, P<0.001)$ and without aphids ( $T=6.96$, df $=37, P<0.001)$, whereas the presence of aphids did not improve the acceptability of plants with larval residues $(T=1.43, \mathrm{df}=37, P=0.16)$ or without $(T$ $=1.41, \mathrm{df}=37, P=0.22$ ).

\section{Heterospecific larval residues}

We obtained $63 H$. convergens females that laid one or more egg clusters in a trial, with four females failing to lay within the $48 \mathrm{~h}$ period. A total of 105 clusters were obtained containing a total of 1920 eggs (mean \pm SEM $=$ $18.3 \pm 0.9$ eggs per cluster). There were no significant differences in the sizes of clusters laid on plants of the four different types or elsewhere in the arena $(F=0.73$, df $=4, P=0.57)$. Only 7 females laid clusters on elements of the arena without laying on a plant and $81.9 \%$ of clusters were laid on plants, a significantly larger proportion than in the experiment with conspecific larvae (Test of proportions, $P<0.001$; StatSoft, 2000).

The number of egg masses obtained on plants of the four types is depicted in Fig. 2. Significantly more egg clusters were laid on clean plants than would be expected by chance $\left(\chi^{2}=8.48,0.05<\alpha<0.1\right)$, and significantly fewer occurred on plants with larval residues $\left(\chi^{2}=9.78\right.$, $0.05<\alpha<0.1)$. Plants with aphids and plants with both aphids and larval residues received egg clusters at rates not significantly different from what would be expected by chance $\left(\chi^{2}=1.96, \alpha>0.05\right.$, and $\chi^{2}=1.41, \alpha>0.05$, respectively). Pairwise comparisons revealed that the presence of larval residues reduced the acceptability of clean plants $(T=4.66, \mathrm{df}=62, P<0.001)$, but not plants with aphids $(T=1.94,62 \mathrm{df}, P=0.057)$. In contrast, the presence of aphids alone did not affect the acceptability of otherwise clean plants $(T=0.88, \mathrm{df}=62, P=0.382)$, or plants with larval residues $(T=1.92, \mathrm{df}=62, P=$ 0.06).

\section{Larval egg consumption}

Thirty nine of 46 third instar $C$. maculata consumed eggs from one or more clusters within $24 \mathrm{~h}$ when presented simultaneously with similar-sized egg masses of their own species and those of $H$. convergens. These larvae consumed similar mean $( \pm$ SEM) numbers of both egg types $(C$. maculata: $5.6 \pm 0.9, H$. convergens: $6.3 \pm$ $1.0, T=0.84, \mathrm{df}=38, P=0.42)$. Since eggs of only one type were consumed in 18 replicates, it seemed possible that these larvae might have failed to encounter the second egg mass. Consequently, we examined separately the 21 replicates in which eggs of both types were consumed, but there was still no significant difference in the number consumed $(T=1.10$, df $=20, P=0.297)$, although there was a marginally significant tendency for larvae to consume a larger proportion of the available conspecific eggs $(T=2.07, \mathrm{df}=20, P=0.05)$.

Twenty one of 22 third instar $H$. convergens presented simultaneously with similar-sized egg masses of their own species and those of $C$. maculata consumed eggs from one or more clusters in all but one replicate within $24 \mathrm{~h}$. These larvae consumed very few eggs of $C$. maculata $($ mean $=2.2 \pm 0.7)$ and significantly more conspecific eggs $($ mean $=10.9 \pm 1.9, T=4.08, \mathrm{df}=20, P=0.001)$.

\section{DISCUSSION}

Gravid female $H$. convergens did not lay any egg masses on sorghum plants that were contaminated with residues of conspecific larvae and lacked aphids (Fig. 1). Plants bearing aphids and residues of conspecific larvae received only three egg masses, and two of these were laid by the same female. In contrast, plants bearing aphids only received similar numbers of egg masses as expected by chance, and clean plants, more egg clusters than expected by chance. Similar repellency of conspecific larval residues was demonstrated by Růžička (1997) for Coccinella septempunctata L. and Růžička (2003) for Cycloneda limbifer Casey and Semiadalia undecimnotata (Schneider) using filter papers as ovipositional substrates. In this study, we obtained ovipositions on plants, with females tested in solitude, as opposed to laying in groups, and tallied egg masses instead of total eggs, a more conservative measure of female decision-making.

So repellent were conspecific larval residues that fully $50 \%$ of females tested avoided the plants for oviposition entirely and laid eggs elsewhere in the arena, a significantly larger proportion than in the trials with $C$. maculata larval residues. Females repeatedly replaced within the arena sometimes took flight, a behavior otherwise rarely observed in gravid females, landing on the cage screen and often coming to rest in the upper corners of the cage. Being unable to abandon the arena, most finally laid egg clusters on the screen or on other elements of the 
arena as distant as possible from the plants. Among the plant types offered, clean plants received the most egg clusters, significantly more than would be expected by chance. Although females did not avoid aphid-bearing plants, the presence of aphids did not increase the acceptability of plants contaminated with larval residues, suggesting that any positive response to aphids was more than offset by negative responses to conspecific larval residues. Hemptinne \& Dixon (2000) extracted the larval tracks of $A$. bipunctata and found a mixture of alkanes, some of which were also present in chloroform washes of the adult elytra and egg chorion, and suggested that this group of compounds has multiple semiochemical functions in coccinellids that include mate-recognition, defence, and oviposition deterrence. Later, Laubertie et al. (2006) demonstrated that the larval semiochemicals inhibitory to $A$. bipunctata females were deposited via the anal disk, a structure that is typically used by coccinellid larvae for adhesion to plant surfaces. In addition, Růžička (2002) demonstrated that the activity of these larval residues can persist for periods ranging from 10-30 d.

Although $H$. convergens females clearly recognized the presence of $C$. maculata larval residues on plants and tended to be repelled by them, the repellency did not appear to be as strong as that exhibited to residues of conspecific larvae, and this was reflected in the smaller proportion of females that avoided plants entirely for oviposition. Clean plants were once again favored among the plant types offered, receiving significantly more egg clusters than expected by chance (Fig. 2). Once again, plants with larval residues that lacked aphids received fewer egg masses than expected by chance, and the presence of aphids did not significantly increase the acceptability of plants with larval residues. In contrast to the trials with conspecific larvae, the presense of aphids alone increased the acceptability of clean plants, suggesting they did act as a positive stimulus.

Doumbia et al. (1998) reported oviposition deterrency of conspecific larval tracks for $C$. septempunctata and $A$. bipunctata, but failed to detect any heterospecific responses in either species. Oliver et al. (2006) found that gravid Aphidecta obliterata (L.) females were deterred from oviposition by conspecific larval residues, but not by those of $A$. bipunctata. Similarly, Yasuda et al. (2000) found that Harmonia axyridis Pallas females were deterred from ovipositing by conspecific, but not by heterospecific (C. septempunctata) larval residues. In tests with $C$. septempunctata, C. limbifer, Leis dimidiata $(\mathrm{F}$.) and S. undecimnotata, Růžička (2001) found that some species were deterred from oviposition by heterospecific larval residues of certain other species, but only in a minority of cases. Růžička (2006) found Cheilomenes sexmaculata (F.) females to be repelled by larval residues of Cycloneda limbifer Casey and Ceratomegilla (Semiadalia) undecimnotata (Schneider), although not by those of Harmonia dimidiata (F.). The negative findings of some of these previous studies with respect to heterospecific responses likely derive from interactions between species that are either ecologically or geographically dis- parate. Our finding that $H$. convergens responds to larval residues of $C$. maculata is consistent with substantial niche overlap between these two species and may indicate that the latter species represents a significant egg predation threat. This inference is supported by the results of the consumption assay which revealed that $C$. maculata larval consumed $H$. convergens eggs as readily as conspecific eggs, although the reverse was not true. It is also consistent with the findings of Schellhorn \& Andow (1999b) who studied sources of mortality for egg masses of C. maculata and A. bipunctata in field corn. Their findings indicated partial niche overlap between the two species and implicated the importance of cannibalism as equal to, or greater than, that of interspecific predation as a source of egg mortality for both species.

It bears noting that $H$. convergens egg clusters are typically found only on aphid-infested sorghum plants in the field and are not normally found on uninfested plants. For example, examination of 160 whorl-stage sorghum plants in a planting at the Agricultural Research Center at Hays, Kansas on July 2, 2006 revealed 27 coccinellid egg clusters, the majority of which were assumed to be $H$. convergens on the basis of adult counts, although a few adult $C$. maculata were also present. All of these egg clusters were found on the lower leaves or stems of plants with large, established Rhopalosiphum maidis Fitch colonies higher up in the whorl and, in a few cases, small, nuclear colonies of $S$. graminum on the undersides of lower leaves. None of the 80 uninfested plants examined bore egg clusters, even though many of these were selected adjacent to infested plants. However, the spatial scale at which experiments are performed can influence insect behavior and effects of scale on coccinellid foraging patterns have been demonstrated in the field (Ives et al., 1993). We suspect that the high rates of oviposition we observed on uninfested plants likely arise as an artifact of the relatively small scale of the arena combined with a tendency of $H$. convergens females to select uninfested plant parts for oviposition. Sorghum plants in the field are typically much larger than our experimental plants by the time they support established aphid colonies and $H$. convergens egg masses are typically placed on the undersides of lower, uninfested leaves some $30-50 \mathrm{~cm}$ distant from the aphid colony. This was a distance that could not be achieved within the study arenas in which plants were separated by only $15 \mathrm{~cm}$.

Interestingly, residues of conspecific developmental stages may actually serve as ovipositional attractants in some insect species such as sand flies (Basimike, 1997). In such cases, it seems likely that the stimulus is used merely as an indicator of environmental conditions suitable for larval development when cannibalism does not represent a significant mortality risk for immature stages. In aphid predators, cannibalism of eggs and other larvae appears to be the rule, rather than the exception and has been well documented in both Chrysopidae (Canard \& Duelli, 1983; Michaud, 2001) and Syrphidae (Branquart et al., 1997; Belliure \& Michaud, 2001). In the Coccinellidae especially, the importance of cannibalism for larval 
survival cannot be overestimated. For example, larvae of Propylea japonica Mulsant can complete the first instar when fed just two conspecific eggs (Wang \& Wei, 1990) and a monotypic diet of conspecific eggs typically supports completed development in those species tested (Michaud, 2002; Cottrell, 2004; Pervez et al., 2006). Consumption of just one or a few conspecific eggs by first instars has been shown to significantly enhance fitness in a number of species even on highly suitable larval diets (Osawa, 2002; Michaud \& Grant, 2004).

If egg masses are at high risk of cannibalism and predation, it follows that ovipositing females should respond to chemicals signaling the presence of conspecific and heterospecific larvae (oviposition-deterring pheromones and synomones, respectively) and distance their egg masses from such residues accordingly. However, as egg masses are placed at increasing distances from larval residues, so they become more distant from their essential food supply, the aphid colonies that are typically associated with foraging larvae. A similar risk trade-off associated with proximity to aphid colonies has been inferred for molting and pupation site selection by $C$. maculata larvae (Lucas et al., 2000). Ironically, sibling egg cannibalism by hatching larvae undoubtedly increases their effective foraging radius and likely serves to increase the distance from the aphid colony an egg mass can be placed without endangering larval survival. Thus, oviposition site selection by female coccinellids likely reflects a trade-off between two opposing risk factors: potential progeny starvation if eggs are laid too distant from the food supply, versus their potential loss to cannibalism or predation if they are laid in too close proximity. As suggested by others (Doumbia et al., 1998; Růžička, 2001), the net effect at larger spatial scales is probably a more even distribution of coccinellid eggs and larvae among available aphid colonies.

ACKNOWLEDGEMENTS. The authors wish to thank $P$. Sloderbeck and two anonymous reviewers for their improvements of the MS. Voucher specimens of $H$. convergens and $C$. maculata are deposited at the Prairie Museum of Arthropod Research in Manhattan, Kansas under reference number 192. This publication is contribution no. 07-44-5 of the Kansas State Agricultural Experiment Station.

\section{REFERENCES}

BASIMIKE M. 1997: Oviposition attractant associated with conspecific development stages of Sergentomyia and Phlebotomus sandflies (Dipt., Psychodidae). J. Appl. Entomol. 121: 545-548.

Belliure B. \& Michaud J.P. 2001: Biology and behavior of Pseudodorus clavatus (F.) (Diptera: Syrphidae), an important predator of citrus aphids. Ann. Entomol. Soc. Am. 94: 91-96.

Branquart E., Hemptinne J.L., Bauffe C. \& Benfekih L. 1997: Cannibalism in Episyrphus balteatus (Dipt.: Syrphidae). Entomophaga 42: 145-152.

Brewer M.J. \& Elliott N.C. 2004: Biological control of cereal aphids in North America and mediating effects of host plant and habitat manipulations. Annu. Rev. Entomol. 49: 219-242.

CAnard M. \& Duelli P. 1983: Predatory behavior of larvae and cannibalism. In Canard M., Semeria Y. \& New T.R. (eds):
Biology of Chrysopidae. Series Entomologica 27. W. Junk, The Hague, pp. 92-100.

CotTRell T.E. 2004: Suitability of exotic and native lady beetle eggs (Coleoptera: Coccinellidae) for development of lady beetle larvae. Biol. Control 31: 362-371.

Cottrell T.E. 2005: Predation and cannibalism of lady beetle eggs by adult lady beetles. Biol. Control 34: 159-164.

Doumbia M., Hemptinne J.L. \& Dixon A.F.G. 1998: Assessment of patch quality by ladybirds: role of larval tracks. Oecologia 113: 197-202.

Elliott N.C. \& KieckHEFer R.W. 2000: Response by coccinellids to spatial variation in cereal aphid density. Pop. Ecol. 42: 81-90.

Frechette B., Dixon A.F.G, Alauzet C. \& Hemptinne J.L. 2004: Age and experience influence patch assessment for oviposition by an insect predator. Ecol. Entomol. 29: 578-583.

Gagne I., Coderre D. \& Mauffette Y. 2002: Egg cannibalism by Coleomegilla maculata lengi neonates: Preference even in the presence of essential prey. Ecol. Entomol. 27: 285-291.

Gordon R.D. 1985: The Coccinellidae (Coleoptera) of North America north of Mexico. J. N.Y. Entomol. Soc. 93: 1-912.

Hagen K.S. 1962: Biology and ecology of predaceous Coccinellidae. Annu. Rev. Entomol. 7: 289-326.

Hemptinne J.L. \& Dixon A.F.G. 1991: Why have ladybirds generally been so ineffective in biological control? In Polgar L., Chambers R.J., Dixon A.F.G. \& Hodek I. (eds): Behaviour and Impact of Aphidophaga. SPB Publishing, The Hague, pp. $140-157$.

Hemptinne J.L. \& Dixon A.F.G. 2000: Defence, oviposition and sex: semiochemical parsimony in two species of ladybird beetles (Coleoptera: Coccinellidae)? A short review. Eur. J. Entomol. 97: 443-447.

Hemptinne J.L., Dixon A.F.G., Doucet J.L. \& Petersen J.E. 1993: Optimal foraging by hoverflies (Diptera: Syrphidae) and ladybirds (Coleoptera: Coccinellidae): Mechanisms. Eur. J. Entomol. 90: 451-455.

Ives A.R., Kareiva P. \& Perry R. 1993: Response of a predator to variation in prey density at three hierarchical scales: lady beetles feeding on aphids. Ecology 74: 1929-1938.

Kindlmann P. \& Dixon A.F.G. 1993: Optimal foraging in ladybeetles (Coleoptera: Coccinellidae) and its consequences for their use in biological control. Eur. J. Entomol. 90: 443-450.

KRING T.J. \& GILSTRAP F.E. 1983: Within-field distribution of greenbug (Homoptera: Aphididae) and its parasitoids in Texas winter wheat. J. Econ. Entomol. 76: 57-62.

Laubertie E., Martini X., Cadena C., Treilhou M., Dixon A.F.G. \& Hemptinne J.L. 2006: The immediate source of the oviposition-deterring pheromone produced by larvae of Adalia bipunctata (L.) (Coleoptera, Coccinellidae). J. Insect Behav. 19: 231-240.

Lucas E., Coderre D. \& Brodeur J. 2000: Selection of molting and pupation sites by Coleomegilla maculata (Coleoptera: Coccinellidae): Avoidance of intraguild predation. Environ. Entomol. 29: 454-459.

Michaud J.P. 1999: Aggregation by alatae of Toxoptera citricida (Homoptera: Aphididae). Environ. Entomol. 28: 205-211.

Michaud J.P. 2001: Evaluation of green lacewings, Chrysoperla plorabunda Fitch (Neuroptera: Chrysopidae) for augmentative release against brown citrus aphid, Toxoptera citricida (Homoptera: Aphididae) in citrus. J. Appl. Entomol. 125: 383-388.

Michaud J.P. 2002: Invasion of the Florida citrus ecosystem by Harmonia axyridis (Coleoptera: Coccinellidae) and asymmetric competition with a native ladybeetle, Cycloneda sanguinea. Environ. Entomol. 31: 827-835. 
Michaud J.P. \& Grant A.K. 2004: Adaptive significance of sibling egg cannibalism in Coccinellidae: Comparative evidence from three species. Ann. Entomol. Soc. Am. 97: 710-719.

Michaud J.P. \& Mackauer M. 1995: The oviposition behavior of Monoctonus paulensis (Ashmead) (Hymenoptera: Aphidiidae): Factors influencing reproductive allocation to hosts and host patches. Ann. Entomol. Soc. Am. 88: 220-226.

MichAUD J.P. \& QURESHI J.A. 2005: Induction of reproductive diapause in Hippodamia convergens (Coleoptera: Coccinellidae) hinges on prey quality and availability. Eur. J. Entomol. 102: 483-487.

Michaud J.P. \& QURESHI J.A. 2006: Reproductive diapause in Hippodamia convergens and its life history consequences. Biol. Control 39: 193-200.

Michels G.J. Jr., Elliot N.C., Romero R.A., Fritts D.A. \& BIBLE J.B. 2001: Impact of indigenous coccinellids on Russian wheat aphids and greenbugs (Homoptera: Aphididae) infesting winter wheat in the Texas Panhandle. Southwest. Entomol. 26: 97-114.

MiLls N.J. 1982: Voracity, cannibalism and coccinellid predation. Ann. Appl. Biol. 101: 144-148.

Oliver T.H., Timms J.E.L., Taylor A. \& Leather S.R. 2006 Oviposition responses to patch quality in the larch ladybird Aphidecta obliterata (Coleoptera: Coccinellidae): effects of aphid density, and con- and heterospecific tracks. Bull. Entomol. Res. 96: 25-34.

Osawa N. 2002: Sex-dependent effects of sibling cannibalism on life history traits of the ladybird beetle Harmonia axyridis (Coleoptera: Coccinellidae). Biol. J. Linn. Soc. 76: 349-360.

Pennachio F. \& Tremblay E. 1986: Spatial distribution and field sampling of lucerne aphids: Acyrthosiphum pisum (Harris) and Therioaphis trifolii f. maculata (Monell) (Homoptera: Aphididae). Frust. Entomol. 9: 9-21.

Pervez A., Gupta A.K. \& OmKar 2006: Larval cannibalism in aphidophagous ladybirds: Influencing factors, benefits and costs. Biol. Control 38: 207-213.

Rohlf F.J. \& SoKal R.R. 1969: Statistical Tables. W.H. Freeman, San Fransisco, 253 pp.

RŮŽIČKA Z. 1994: Oviposition-deterring pheromone in Chrysopa oculata (Neuroptera: Chrysopidae). Eur. J. Entomol. 91: 361-370.

RŮŽIČKA Z. 1997: Recognition of oviposition-deterring allomones by aphidophagous predators (Neuroptera: Chrysop- idae, Coleoptera: Coccinellidae). Eur. J. Entomol. 94: 431-434.

RŮžIČKA Z. 2001: Oviposition responses of aphidophagous coccinellids to tracks of ladybird (Coleoptera: Coccinellidae) and lacewing (Neuroptera: Chrysopidae) larvae. Eur. J. Entomol. 98: $183-188$.

RŮŽIČKA Z. 2002: Persistence of deterrent larval tracks in Coccinella septempunctata, Cycloneda limbifer, and Semiadalia undecimnotata (Coleoptera: Coccinellidae). Eur. J. Entomol. 99: 471-475.

RỦŽıČKA Z. 2003: Perception of oviposition-deterring larval tracks in aphidophagous coccinellids Cycloneda limbifer and Ceratomegilla undecimnotata (Coleoptera: Coccinellidae). Eur. J. Entomol. 100: 345-350.

RỦŽIČKA Z. 2006: Oviposition-deterring effects of conspecific and heterospecific larval tracks on Cheilomenes sexmaculata (Coleoptera: Coccinellidae). Eur. J. Entomol. 103: 765-771.

SCHELLHORN N.A. \& ANDOw D.A. 1999a: Mortality of coccinellid (Coleoptera: Coccinellidae) larvae and pupae when prey become scarce. Environ. Entomol. 28: 1092-1100.

SCHELLHORN N.A. \& ANDOw D.A. 1999b: Cannibalism and interspecific predation: role of oviposition behavior. Ecol. Appl. 9: $418-428$.

SCHELLhorn N.A. \& ANDOw D.A. 2005: Response of coccinellids to their aphid prey at different spatial scales. Pop. Ecol. 47: 71-76.

Scholz D. \& Poenling H.M. 2000: Oviposition site selection in Episyrphus balteatus. Entomol. Exp. Appl. 94: 149-158.

SPSS 1998: SPSS 8.0 for windows. SPSS Inc., Prentice Hall, New Jersey.

StatSoft 2000: Statistica for Windows. Tulsa, OK.

WANG G. \& WeI J.H. 1990: Study on the cannibalistic behavior of Propylea japonica on its eggs. Nat. Enem. Ins. 12: 101-104.

Wratten S.D. 1974: Aggregation in the birch aphid Euceraphis punctipennis (Zett.) in relation to food quality. J. Anim. Ecol. 43: 191-198.

Yasuda H., TAKagi T. \& KogI G. 2000: Effects of conspecific and heterospecific larval tracks on the oviposition behaviour of the predatory ladybird Harmonia axyridis (Coleoptera: Coccinellidae). Eur. J. Entomol. 97: 551-553.

Received January 30, 2007; revised and accepted March 23, 2007 